\title{
Calculation on Variable Sag in Chain Drives
}

\author{
Changfa Rong \\ School of Mechanical Engineering, Hebei University of Technology, Tianjin, China \\ Email: Rongchangfa@126.com
}

Received 22 April 2016; accepted 7 May 2016; published 10 May 2016

Copyright (c) 2016 by author and OALib.

This work is licensed under the Creative Commons Attribution International License (CC BY). http://creativecommons.org/licenses/by/4.0/

\section{c. (i) Open Access}

\begin{abstract}
This paper presents a computer-aided analysis to calculate sag in chain drives exactly, which is commonly used in mechanical power transmission. With sprocket rotating, sag in chain drives is different. Sag is a function of meshing position of chain and sprocket. Because sag in chain drives is a variable, the maximum and minimum sag can be obtained by numerical calculation. Corresponding tensions in slack chain are obtained. A computer programme to calculate sag and tensions in slack chain is programmed.
\end{abstract}

\section{Keywords}

Chain Drives, Variable Sag, Computer-Aided Analysis

Subject Areas: Mechanical Engineering

\section{Introduction}

Chain drives are widely used in mechanical engineering. It is useful to calculate sag exactly in practice. In the past, calculation of sag in chain drives is approximate calculation under a series of assumable conditions. These assumable conditions are far different from practical condition of chain drives. In some methods sprocket's polygon is replaced with pitch circle. But sag in chain drives is variable due to polygonal action. These methods to calculate sag in chain drives have bigger error. This paper presents a computer-aided analysis to calculate sag in chain drives exactly. Because sag in chain drives is a variable, the maximum and minimum sag can be obtained by numerical calculations. Corresponding tensions in slack chain are obtained. A computer programme is made.

\section{Determination of Geometrical Shape of Slack Chain Drives}

Slack chain sink due to chain weight, slack chain can be considered a slick cure that called catenary, catenary’s equation [1]

$$
y=\operatorname{ach} \frac{x}{a}
$$


Suppose end of slack chain drives are $\left(x_{1}, y_{1}\right)$ and $\left(x_{2}, y_{2}\right)$, shown on Figure 1.

Suppose $x_{2}-x_{1}=L \quad y_{2}-y_{1}=H$

$$
\begin{aligned}
& L=x_{2}-x_{1}=C \cos \alpha_{C}-R_{1} \cos \left(\theta_{t}-\alpha_{C}\right)+R_{2} \cos \left(\varphi_{t}-\alpha_{C}\right) \\
& H=y_{2}-y_{1}=C \sin \alpha_{C}+R_{1} \sin \left(\theta_{t}-\alpha_{C}\right)-R_{2} \cos \left(\varphi_{t}-\alpha_{C}\right)
\end{aligned}
$$

Form references [2], we can know

$$
s=L_{c}-L_{t}-\left(Z_{1}-K_{1}\right) p-K_{2} p
$$

In above equations:

$C$-center distance

$R_{1}, R_{2}$-pitch radius of driving or driven sprocket;

$Z_{1}, Z_{2}$ - number of teeth of driving or driven sprocket;

$p$ - chain pitch

$\alpha_{C}$-Angle between horizontal line and centerline of chain drive

$s$-length of slack chain

$L_{c}$ - chain length

$L_{t}$-tight chain length

$K_{1}, K_{2}$ - coefficient determined in reference [2]

From reference [2], we have

$$
s=\int_{x_{1}}^{x_{2}} \sqrt{1+y^{\prime 2}} \mathrm{~d} x=\operatorname{ash} \frac{x_{2}}{a}-\operatorname{ash} \frac{x_{1}}{a}
$$

From Equations (1), (5) and $H=y_{2}-y_{1}$, we have

$$
\begin{aligned}
& \mathrm{e}^{\frac{x_{1}}{a}}\left(\mathrm{e}^{\frac{L_{1}}{a}}-1\right)=\frac{H+s}{a} \\
& \mathrm{e}^{-\frac{x_{1}}{a}}\left(\mathrm{e}^{-\frac{L_{1}}{a}}-1\right)=\frac{H-s}{a}
\end{aligned}
$$

To multiply Equation (6) by Equation (7), and order $x=\frac{L}{a}, \frac{s^{2}-H^{2}}{2 L^{2}}=K$, we have

$$
\operatorname{ch} x-1-K x^{2}=0
$$

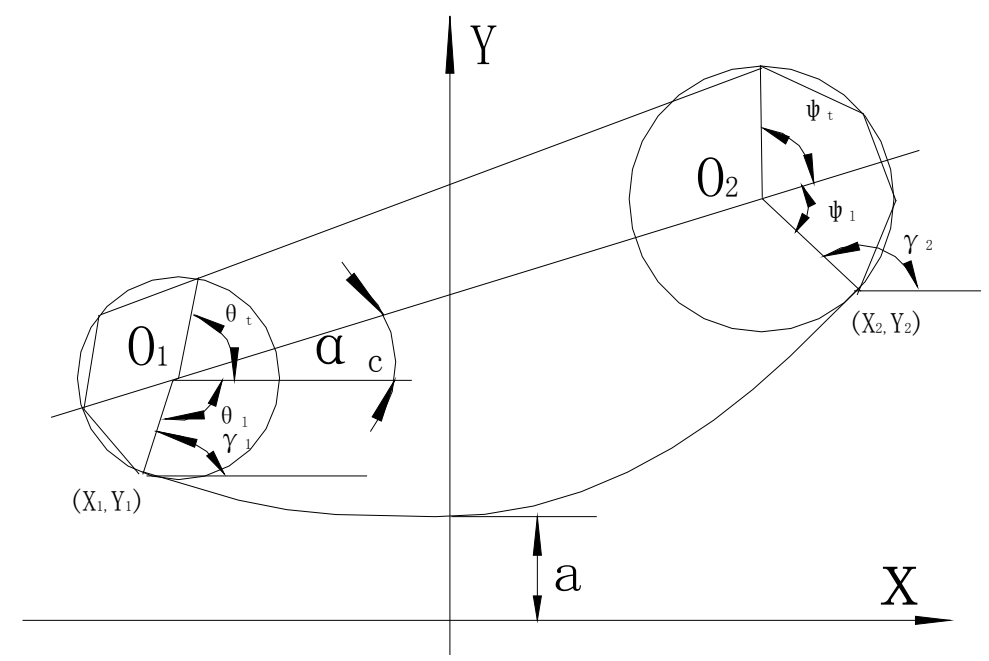

Figure 1. Chain drives. 
Equation (8) is exceeding equation. Equation (8) can be solved with Newton iterative method. Numerical result of $a$ can be gained.

\section{Determination of Principle of End Points of Slack Chain and Corresponding Coordinate Values}

When slack chain is tight, end point of slack chain can be determined with $\theta_{t}, \psi_{t}$

$$
\theta_{l}=K_{1} \frac{2 \pi}{Z_{1}}-\theta_{t} \quad \psi_{l}=K_{2} \frac{2 \pi}{Z_{2}}-\phi_{t}
$$

In Equation (9), $\theta_{t}, \psi_{t}$ are angle displacement of driving and driven sprocket.

Because polygonal action and fixed center distance, line is not integer number of pitch, whose end determined by $\theta$ and $\phi$ points are $\left(X_{1}, Y_{1}\right)$ and $\left(X_{2}, Y_{2}\right)$. Only when slack chain has sag, length of slack chain can be integer number of pitch.

$F_{1}$-Force between chain link on sprocket and roller, $\mathrm{N} \mathrm{F}_{2}$-Force between teeth of sprocket and roller, $\mathrm{N}$ $T$-Force between roller chain and roller, $\mathrm{N} \alpha$-pressure angle

When the angle between sprocket and chain link is outside concave, force of roller shown in Figure 2(a). From Figure 2(a), it is known force in roller is not in balance. Resultant force can make roller go along teeth of sprocket or make roller go out of sprocket.

When the angle between sprocket and chain link is outside protruding, force in roller is in balance force of roller shown in Figure 2(b).

To sum up, the angle between sprocket and chain link should be outside protruding and not outside concave.

When he angle between sprocket and chain link is outside protruding,

$$
\alpha_{\mathrm{s}}<\alpha \quad \beta_{\mathrm{s}}<\beta
$$

From equation of slack chain of chain drive, we have

$$
\alpha_{S}=\operatorname{arctg}\left(\left|\operatorname{sh} \frac{x_{1}}{a}\right|\right) \quad \beta_{s}=\operatorname{arctg}\left(\left|\operatorname{sh} \frac{x_{2}}{a}\right|\right)
$$

From Figure 1 and Figure 3, we have

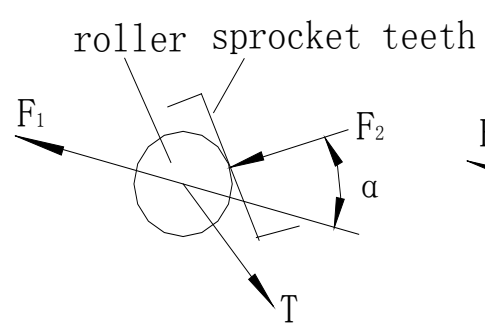

(a)

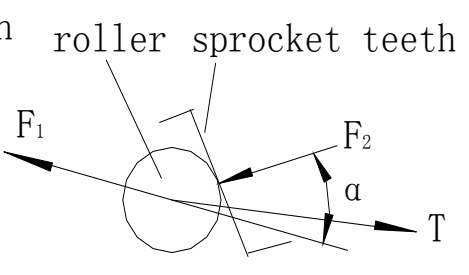

(b)

Figure 2. Force diagram of roller in chain drives.

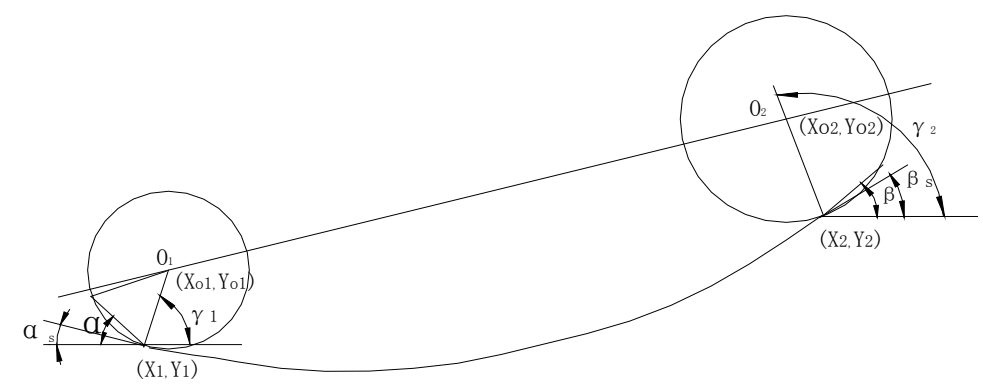

Figure 3. Analysis and calculation of chain drives. 


$$
\begin{array}{cc}
\gamma_{1}=180^{\circ}-\left(\theta_{l}-\alpha_{c}\right) & \gamma_{2}=180^{\circ}-\left(\psi_{l}-\alpha_{c}\right) \\
\alpha=\left(\theta_{l}-\alpha_{C}\right)-\left(90^{\circ}-\frac{180^{\circ}}{Z_{1}}\right) & \beta=90^{\circ}+\frac{180^{\circ}}{Z_{2}}-\left(\phi_{l}-\alpha_{C}\right)
\end{array}
$$

When slack chain is tight, $\mathrm{L}, \mathrm{H}$ and s can be gained by Equation (2)-(4). Points of slack chain $\left(X_{1}, Y_{1}\right)$ and $\left(X_{2}\right.$, $Y_{2}$ ) can be calculated by Newton iterative method with Equations (6), (2) and (1).

A program to calculate coordinate value of end point is programmed based on Figure 4.

\section{Calculation of Sag and Tensions in Slack Chain}

\subsection{Calculation of Sag in Chain Drive}

Equation of line between two end points of slack chain is shown in Figure 1.

$$
Y=y_{1}+\frac{y_{2}-y_{1}}{x_{2}-x_{1}}\left(X-x_{1}\right)
$$

Equation of slack chain: $y=\operatorname{ach} \frac{x}{a}$

Sag in Chain Drives: $f=\max (Y-y)$

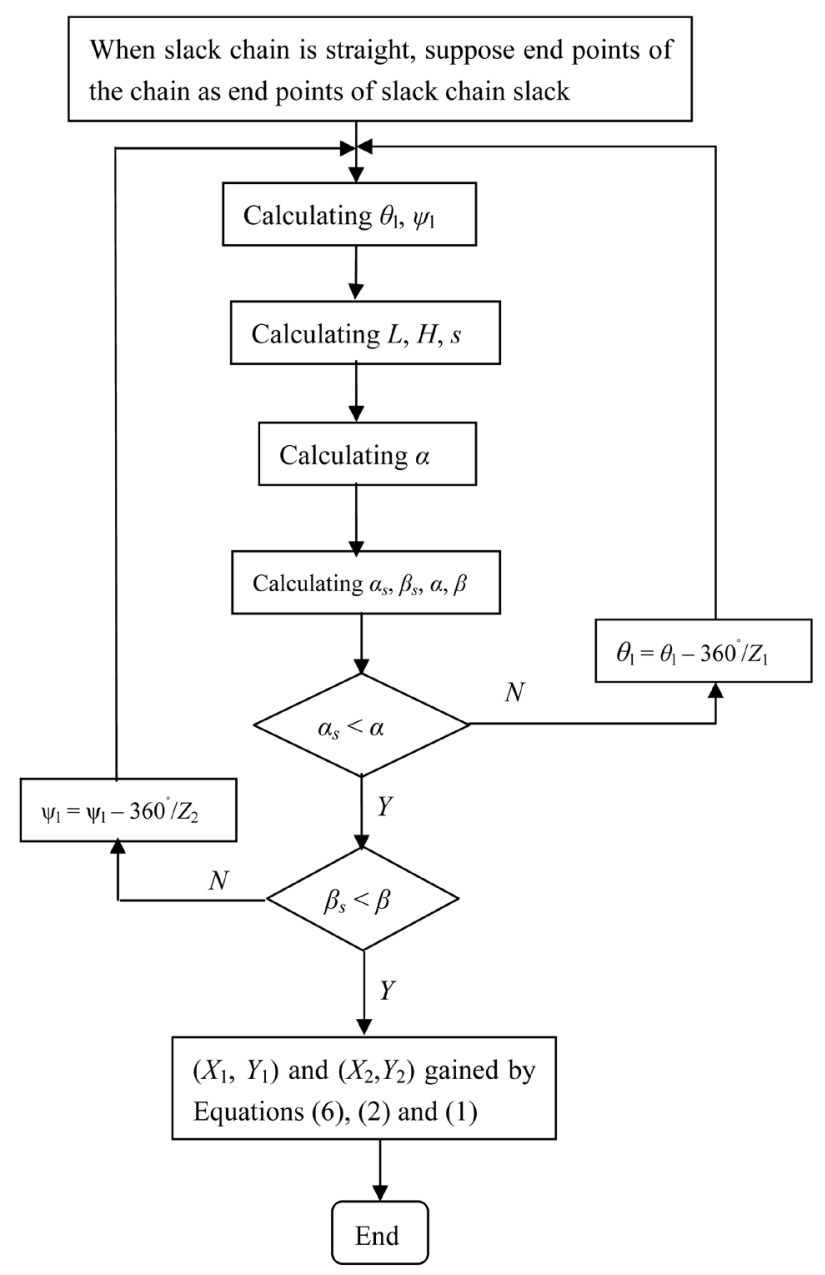

Figure 4. Flowchart to calculate end points of slack chain in chain drives. 
$f$-Sag in Chain Drives, $\mathrm{mm}$

When $x$ belong to area $\left(X_{1}, Y_{1}\right), X$ can has a serious of values. So we can have accurate sag in chain drive enough.

\subsection{Calculation of Tensions in Slack Chain}

As shown in Figure 5, $T_{1}, T_{2}$ are tensions of end point slack chain. $q$ is unit weight of roller chain $(\mathrm{N}) . s_{1}$ is length of slack chain between $\left(X_{1}, Y_{1}\right)$ and $(0, a)$. $s_{2}$ is length of slack chain between $(0, a)$ and $\left(X_{2}, Y_{2}\right)$. $H_{0}$ is tension at point $(0, a)$.

$$
T_{1}=q s_{1} / \sin \theta_{1}=q s_{1}\left(1+1 / \operatorname{tg}^{2} \theta_{1}\right)^{\frac{1}{2}}
$$

By Equations (1), (5) and Equation (16), we have

$$
\begin{aligned}
& T_{1}=\operatorname{qash} \frac{x_{1}}{a_{1}}\left(1+1 / \operatorname{sh}^{2} \frac{x_{1}}{a}\right)^{\frac{1}{2}} \\
& T_{2}=\operatorname{qash} \frac{x_{2}}{a_{1}}\left(1+1 / \operatorname{sh}^{2} \frac{x_{2}}{a}\right)^{\frac{1}{2}}
\end{aligned}
$$

\section{Example and Conclusions}

A Chain Drive is given. Chain pitch $p=50.8 \mathrm{~mm}$. Number of Sprocket $Z_{1}=20, Z_{2}=50$. Number of Chain link $L_{P}=116$, Unit Weight of Chain $q=0.1 \mathrm{~N} / \mathrm{mm}$.

Calculating results are given in Table 1 . From Table 1 the following conclusions can be gained.
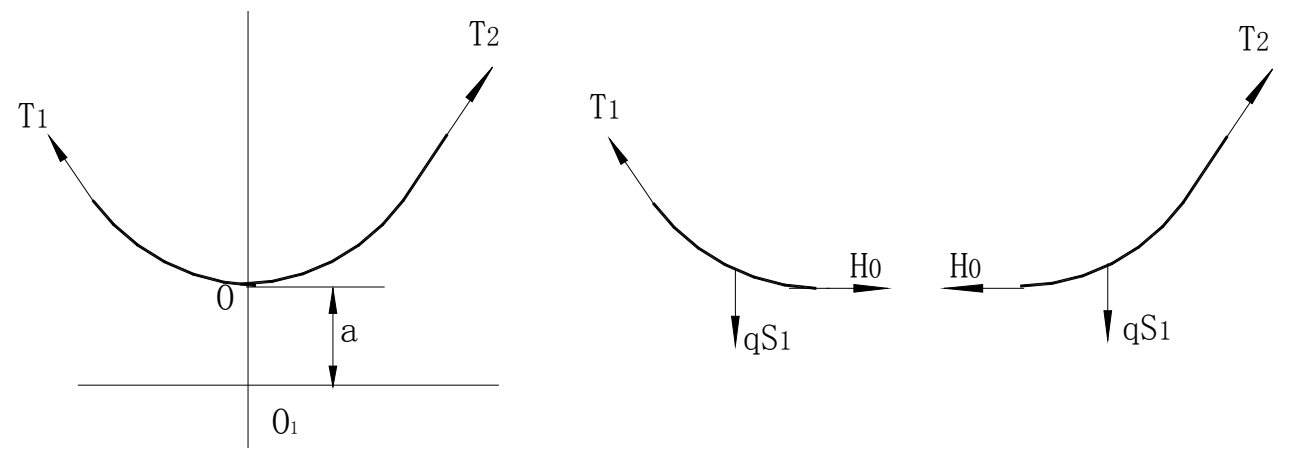

\begin{tabular}{|c|c|c|c|c|c|c|}
\hline $\mathrm{C}(\mathrm{mm})$ & $f_{\max }(\mathrm{mm})$ & $T_{1}(\mathrm{~N})$ & $T_{2}(\mathrm{~N})$ & $f_{\min }(\mathrm{mm})$ & $T_{1}(\mathrm{~N})$ & $T_{2}(\mathrm{~N})$ \\
\hline 2042.96 & 9.777 & 5300.73 & 5276.61 & 0.000 & 6344.76 & 6368.87 \\
\hline 2042.92 & 12.713 & 4078.05 & 4053.94 & 0.252 & 4006.83 & 4530.91 \\
\hline 2042.80 & 18.630 & 2785.06 & 2760.92 & 15.789 & 3280.10 & 3255.98 \\
\hline 2042.60 & 25.427 & 2043.70 & 2019.57 & 23.425 & 2215.90 & 2191.82 \\
\hline 2042.40 & 30.716 & 1694.03 & 1669.92 & 29.360 & 1771.22 & 1747.12 \\
\hline 2042.20 & 35.357 & 1473.53 & 1449.42 & 34.135 & 1525.59 & 1501.50 \\
\hline 2042.00 & 39.452 & 1322.37 & 1298.26 & 38.409 & 1357.67 & 1333.59 \\
\hline 2041.80 & 43.205 & 1208.89 & 1184.75 & 42.218 & 1236.66 & 1212.57 \\
\hline 2041.60 & 46.612 & 1121.67 & 1097.55 & 45.714 & 1143.33 & 1119.29 \\
\hline 2041.40 & 49.747 & 1052.00 & 1027.87 & 48.929 & 1069.29 & 1045.21 \\
\hline 2041.20 & 52.787 & 993.54 & 968.43 & 51.984 & 1007.47 & 983.40 \\
\hline 2041.00 & 55.606 & 943.02 & 918.91 & 54.860 & 955.57 & 931.49 \\
\hline
\end{tabular}

Figure 5. Tensions of slack chain in chain drives.

Table 1. Table of sag and t tension of end point slack chain. 
1) When driving sprocket is running and tight chain is straight, sag in chain drives and tensions of end point of slack chain are changing.

2) A little change in centre distance should make bigger change of sag in chain drives. So when centre distance in chain drive is not adjustable, it must be very careful to design centre distance in chain drives.

\section{References}

[1] Tongji University (1999) Mathematical Analysis. Advanced Education Publishing Company, Beijing, 344-346.

[2] Rong, C.F., Zhu, J. and Xu, H. (2000) Determination of Center Distance of a Roller Chain Drives. Journal of Xian Jiaotong University, 34, 47-51. 